\title{
Transitions of care in anticoagulated patients
}

\author{
This article was published in the following Dove Press journal: \\ Journal of Multidisciplinary Healthcare \\ 19 June 2013 \\ Number of times this article has been viewed
}

\section{Franklin Michota \\ Department of Hospital Medicine, Cleveland Clinic, Cleveland, OH, USA}

Correspondence: Franklin Michota Cleveland Clinic Main Campus, Mail Code M2 Annex, 9500 Euclid Avenue, Cleveland, OH 44195, USA Tel + I 2164440933

Email michotf@ccf.org
Abstract: Anticoagulation is an effective therapeutic means of reducing thrombotic risk in patients with various conditions, including atrial fibrillation, mechanical heart valves, and major surgery. By its nature, anticoagulation increases the risk of bleeding; this risk is particularly high during transitions of care. Established anticoagulants are not ideal, due to requirements for parenteral administration, narrow therapeutic indices, and/or a need for frequent therapeutic monitoring. The development of effective oral anticoagulants that are administered as a fixed dose, have low potential for drug-drug and drug-food interactions, do not require regular anticoagulation monitoring, and are suitable for both inpatient and outpatient use is to be welcomed. Three new oral anticoagulants, the direct thrombin inhibitor, dabigatran etexilate, and the factor Xa inhibitors, rivaroxaban and apixaban, have been approved in the US for reducing the risk of stroke and systemic embolism in patients with nonvalvular atrial fibrillation; rivaroxaban is also approved for prophylaxis and treatment of deep vein thrombosis, which may lead to pulmonary embolism in patients undergoing knee or hip replacement surgery. This review examines current options for anticoagulant therapy, with a focus on maintaining efficacy and safety during transitions of care. The characteristics of dabigatran etexilate, rivaroxaban, and apixaban are discussed in the context of traditional anticoagulant therapy.

Keywords: hemorrhagic events, oral anticoagulation, parenteral anticoagulation, stroke, transitions of care

\section{Introduction}

Anticoagulant therapy reduces thrombotic risk in patients with a number of conditions, including atrial fibrillation (AF), mechanical heart valves, and indications for major surgery. ${ }^{1-4}$ Most such patients require anticoagulation, both during hospitalization and after discharge to community care. Care transitions are periods of vulnerability, ${ }^{5}$ especially for patients receiving anticoagulation. Inadvertent cessation of therapy, medication discrepancies, and fluctuations in or poor monitoring of anticoagulant effect may occur during this period, ${ }^{6-8}$ increasing the potential for over-anticoagulation and under-anticoagulation, and the risk of hemorrhagic events or stroke, respectively. ${ }^{1,9}$

Managing anticoagulation during care transitions is complicated by a range of issues. Several anticoagulants used in hospitalized patients (eg, low-molecular-weight heparin and fondaparinux) are administered parenterally and are challenging for longterm outpatient use. ${ }^{10,11}$ Patients receiving parenteral drugs during hospitalization may transition to oral drugs after discharge. This transition usually requires temporary coadministration of parenteral and oral drugs and necessitates frequent monitoring of anticoagulation intensity. ${ }^{10,11}$ Patients who receive oral anticoagulation while hospitalized 
do not require a change of anticoagulant at discharge; however, oral anticoagulation with the vitamin $\mathrm{K}$ antagonist (VKA) warfarin, until recently the only oral anticoagulant available in the US, can be challenging, particularly during the transition period when patients may experience changes in diet and have concomitant medications. ${ }^{1,12}$ Indeed, warfarin is a leading cause of medication errors and medication-related adverse events. ${ }^{9,13}$

Adverse events associated with warfarin administration often result from failure to maintain therapeutic anticoagulation levels, which are generally measured by the international normalized ratio (INR). ${ }^{7,13}$ In patients with $\mathrm{AF}$, the risk of stroke increases at INR $<2.0$, and the risk of hemorrhage increases at INR $>3.0 .{ }^{1}$ Therefore, it is important that most warfarin-treated patients remain within this narrow INR window during care transitions as well as during maintenance therapy.

This review discusses the safe administration of anticoagulant therapy in several patient groups, with emphasis on the period of transition from hospital to community care. It includes a discussion of the potential of novel oral anticoagulants, such as the direct thrombin inhibitor, dabigatran etexilate, and the direct factor Xa (FXa) inhibitors, rivaroxaban and apixaban, recently approved by the US Food and Drug Administration (FDA), to simplify and improve the safety of the care transition process.

\section{Traditional options for anticoagulant therapy}

Anticoagulants are indicated to reduce the risk of stroke and systemic embolism (SSE) in patients with AF and for the acute treatment and primary and secondary prevention of venous thromboembolism (VTE), among other indications. ${ }^{14}$ Table 1 summarizes the clinical features of anticoagulants most commonly used in the US, as well as others in late clinical development or under FDA review for reduction of stroke risk in AF and/or VTE prophylaxis and treatment.

Parenteral anticoagulants, such as low-molecularweight heparin and fondaparinux, are used for short-term thromboprophylaxis during hospitalization, such as after major orthopedic surgery. ${ }^{14}$ Advantages of low-molecularweight heparin and fondaparinux include rapid achievement of optimal anticoagulant effect, predictable pharmacokinetic and pharmacodynamic properties, a fixed or weight-adjusted dose regimen, and a low risk of clinically significant drug interactions. ${ }^{14,15}$ However, subcutaneous injections may be painful and require technical expertise to administer. Patients receiving parenteral anticoagulants while hospitalized who require long-term anticoagulation are usually transferred to an oral regimen (traditionally warfarin) at the time of hospital discharge. ${ }^{4,16}$

\section{Indications for anticoagulation}

Patients with AF may require anticoagulation because of the nearly five-fold increase in risk of stroke that is associated with this condition. ${ }^{17}$ Meta-analysis of data from six trials involving 2900 patients showed that the risk of stroke in patients with nonvalvular AF could be reduced by $64 \%$ with administration of adjusted-dose warfarin. ${ }^{3}$

Mechanical heart valves predispose to thrombus formation because of flow-induced platelet activation and other stresses on the formed elements in blood. ${ }^{18,19}$ In a meta-analysis of 46 studies that followed 13,008 patients for a total of 53,647 patient-years after implantation of mechanical heart valve prostheses, investigators found a $4 \%$ incidence of major embolism in the absence of antithrombotic therapy. ${ }^{20}$ Antiplatelet therapy reduced the risk to $2.2 \%$, and warfarin anticoagulation further reduced the risk to $1 \%$. The addition of antiplatelet therapy significantly increased the incidence of bleeding but did not further reduce the risk of thromboembolism. ${ }^{20}$ The risk of embolism varied with the type and site of the prosthetic valve. ${ }^{20}$ However, although clinical guidelines recommend that all thrombotic and serious bleeding events following valve replacements be attributed to the prostheses, many such events are simply part of the background incidence of stroke, transient ischemic attack, and major bleeding in the general population. ${ }^{21}$

Major surgery is a documented risk factor for VTE. Major orthopedic surgery, such as knee or hip replacement, ${ }^{2}$ predisposes to both deep vein thrombosis and pulmonary embolism. The latter is particularly serious; without treatment, approximately one-third of patients die. ${ }^{22}$ Thromboprophylaxis has rendered fatal pulmonary embolism uncommon and has reduced the rate of symptomatic VTE within three months of surgery to $1.3 \%$ to $10 \%{ }^{2}$

Atrial fibrillation, mechanical heart valve placement, and major surgery are all conditions in which anticoagulation is indicated to prevent both arterial and venous thromboembolic events. Anticoagulation is also indicated in the treatment of acute VTE, which can arise idiopathically or secondarily to risk factors including cancer, trauma, and intermediate or long-term immobilization. ${ }^{23,24}$ Treatment regimens for acute deep vein thrombosis and pulmonary embolism are similar, but anticoagulant therapy may be more aggressive and/or more prolonged in patients with pulmonary embolism because of an increased risk of recurrence and mortality. ${ }^{23}$ 


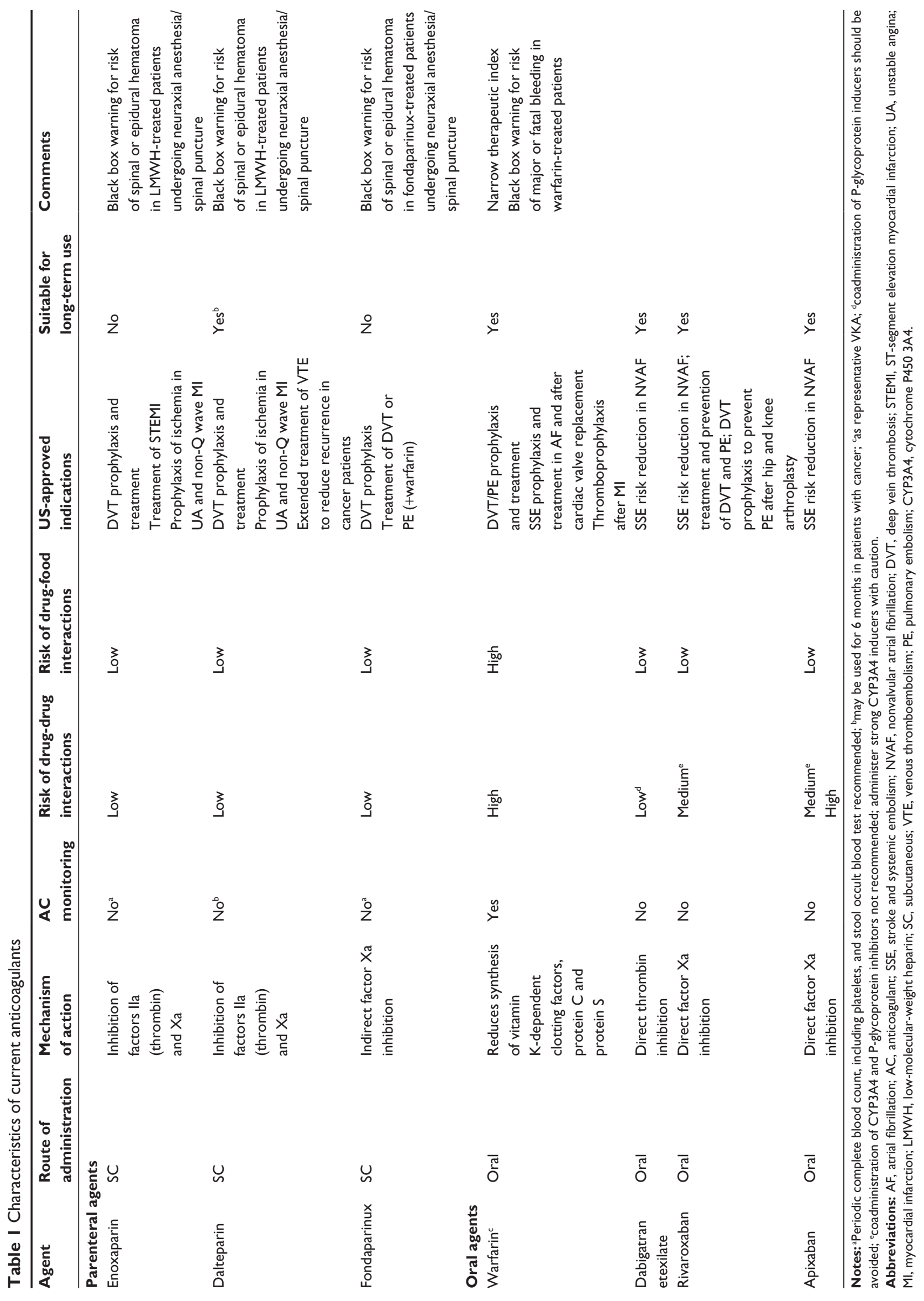




\section{Guidelines for anticoagulation}

The optimal anticoagulant regimen takes into account the magnitude and duration of the risk of thrombosis, as well as whether treatment will take place in the inpatient or outpatient setting (Table 2). For patients with AF, stroke risk can be estimated with a risk stratification scheme. The $\mathrm{CHADS}_{2}$ score assigns one point each for congestive heart failure, hypertension, age $\geq 75$ years, and diabetes, and two points for prior stroke or transient ischemic attack. ${ }^{25}$ The $\mathrm{CHADS}_{2}$ score has been expanded to $\mathrm{CHA}_{2} \mathrm{DS}_{2}$-VASc, which assigns two points each to a history of stroke/transient ischemic attack and age $\geq 75$ years, and one point each to age 65-74 years, female gender, and a history of hypertension, diabetes, recent cardiac failure, or vascular disease. ${ }^{26} \mathrm{In}$ general, guidelines recommend that patients at low risk for stroke $\left(\mathrm{CHADS}_{2}\right.$ or $\mathrm{CHA}_{2} \mathrm{DS}_{2}$-VASc score 0$)$ should receive acetylsalicylic acid or no therapy, those at intermediate risk (score 1) should receive acetylsalicylic acid or oral anticoagulation, and those at high risk (score $\geq 2$ ) should receive oral anticoagulation. ${ }^{26-28}$ Guideline recommendations are reviewed in Table 2.

The thromboprophylactic regimen recommended for patients with prosthetic heart valves is based on valve type (mechanical or bioprosthetic), valve position (aortic or mitral), and the presence of additional risk factors. ${ }^{4}$ In general, mechanical valves are associated with a higher thrombotic risk

Table 2 Guideline recommendations for prevention and treatment of thromboembolism

\begin{tabular}{|c|c|c|}
\hline Patient characteristics & Recommended regimens & Duration of therapy \\
\hline \multicolumn{3}{|l|}{ Atrial fibrillation ${ }^{26-28}$} \\
\hline $\mathrm{CHADS}_{2} / \mathrm{CHA}_{2} \mathrm{DS}_{2}-\mathrm{VASc}$ & - No antithrombotic therapy & Duration of condition \\
\hline score $=0$ & - ASA $75-325$ mg/day & \\
\hline score $=1$ & $\begin{array}{l}\text { - Oral anticoagulation } \\
\text { - Dabigatran etexilate I50 mg bid } \\
\text { - Warfarin (target INR 2.0-3.0) } \\
\text { - ASA 75-325 mg/day } \\
\text { - }\end{array}$ & Duration of condition \\
\hline $\mathrm{CHA}_{2} \mathrm{DS}_{2}$-VASc score $\geq 2$ & $\begin{array}{l}\text { - Oral anticoagulation } \\
\text { - Dabigatran etexilate } 150 \mathrm{mg} \text { bid } \\
\text { - Warfarin (target INR 2.0-3.0) }\end{array}$ & Duration of condition \\
\hline \multicolumn{3}{|c|}{ Prosthetic cardiac valve placement ${ }^{4}$} \\
\hline Mechanical valve & 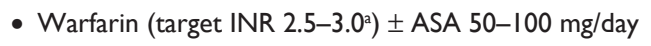 & - Lifelong \\
\hline \multicolumn{3}{|l|}{ Bioprosthetic valve plus } \\
\hline - History of systemic embolism & - Warfarin (target INR 2.5) & - $\geq 3$ months \\
\hline - Existing left atrial thrombus & - Warfarin (target INR 2.5) & - Until thrombus resolution \\
\hline - Increased thromboembolic risk ${ }^{\mathrm{b}}$ & - Warfarin (target INR 2.5) \pm ASA $50-100$ mg/day & - Duration of condition \\
\hline Bioprosthetic mitral valve + no & - Warfarin (target INR 2.5) & - First 3 months \\
\hline $\begin{array}{l}\text { other indication for warfarin } \\
\text { therapy }\end{array}$ & $\begin{array}{l}\text { - Concomitant IV UFH or SC LMWH until INR } \\
\text { in therapeutic range } \\
\text { - ASA } 50-100 \mathrm{mg} / \text { day }\end{array}$ & $\begin{array}{l}\text { - From month } 3 \text { onwards if in } \\
\text { sinus rhythm and no other } \\
\text { indication for continued } \\
\text { VKA therapy }\end{array}$ \\
\hline $\begin{array}{l}\text { Bioprosthetic atrial valve }+ \\
\text { in sinus rhythm and no other } \\
\text { indication for warfarin therapy }\end{array}$ & - ASA 50-100 mg/day & - Lifelong \\
\hline \multirow[t]{2}{*}{ Acute DVT or $\mathrm{PE}^{23}$} & - Rivaroxaban & \\
\hline & $\begin{array}{l}\text { - Warfarin (target INR 2.5) plus: } \\
\text { - LMWH, UFH, or fondaparinux }\end{array}$ & $\begin{array}{l}\text { - } \geq 3 \text { months } \geq 5 \text { days (continue } \\
\text { until INR } \geq 2.0 \text { for } \geq 24 \text { hours) }\end{array}$ \\
\hline \multirow[t]{6}{*}{ Hip arthroplasty ${ }^{2}$} & - Dabigatran etexilate & - $\geq 10-14$ days \\
\hline & - Rivaroxaban & - $\geq 10-14$ days \\
\hline & - Apixaban & - $\geq 10-14$ days \\
\hline & - $\mathrm{LMWH}^{\mathrm{c}}$ & - $>10$ but $\leq 35$ days \\
\hline & - Fondaparinux 2.5 mg/day & - $>10$ but $\leq 35$ days \\
\hline & - Warfarin (target INR 2.5) & - $>10$ but $\leq 35$ days \\
\hline \multirow[t]{3}{*}{ Knee arthroplasty ${ }^{2}$} & - LMWH (high-risk dose) & - $>10$ but $\leq 35$ days \\
\hline & - Fondaparinux 2.5 mg/day & - $>10$ but $\leq 35$ days \\
\hline & - Warfarin (target INR 2.5) & - $>10$ but $\leq 35$ days \\
\hline
\end{tabular}

Notes: ${ }^{a}$ Target INR depends on valve type; beg, atrial fibrillation, low ejection fraction, hypercoagulable state; 'dose regimen depends on timing of treatment initiation. Abbreviations: ASA, acetylsalicylic acid; DVT, deep vein thrombosis; INR, international normalized ratio; IV, intravenous; LMWH, low-molecular-weight heparin; $\mathrm{PE}$, pulmonary embolism; SC, subcutaneous; UFH, unfractionated heparin; VKA, vitamin K antagonist. 
than bioprosthetic valves. The American College of Chest Physicians recommends that patients with mechanical heart valves receive warfarin therapy (target INR 2.5 or 3.0 depending on valve type and position), with concomitant acetylsalicylic acid for those at highest risk. ${ }^{4}$ In contrast, acetylsalicylic acid alone is recommended for long-term therapy in most patients with bioprosthetic valves, although patients at higher risk should receive warfarin monotherapy (target INR 2.5) or warfarin-acetylsalicylic acid combination therapy. ${ }^{4}$

For perioperative antithrombotic management based on the assessment of risk for thromboembolism and bleeding in anticoagulated patients, the American College of Chest Physicians practice guidelines are aimed at simplifying care and keeping the risk of adverse clinical outcomes to a minimum. ${ }^{29}$ When warfarin maintenance therapy must be interrupted prior to surgery, the guidelines recommend stopping warfarin five days before the scheduled intervention. For patients with mechanical heart valves, AF, or VTE, who are at high risk for thromboembolism, the guidelines advise bridging anticoagulation during the period of warfarin interruption; bridging is not advised for patients at low risk. In patients at moderate to high risk receiving acetylsalicylic acid who require noncardiac surgery, the guidelines suggest that acetylsalicylic acid be continued around the time of surgery, rather than stopped 7-10 days before surgery, as in earlier recommendations. For patients requiring dental procedures, the guidelines suggest either continuing warfarin with an oral prohemostatic agent or stopping warfarin 2-3 days before the procedure. ${ }^{29}$

The American College of Chest Physicians recommends that anticoagulation to prevent VTE be administered to all at-risk medical inpatients and moderate-risk to high-risk surgical patients, including those undergoing knee or hip arthroplasty. ${ }^{2,14}$ Depending on risk level, administration of unfractionated heparin, low-molecular-weight heparin, fondaparinux, or warfarin (target INR 2.5; range 2.0-3.0) is recommended. Duration of anticoagulant prophylaxis may range from a minimum of 6-10 days (at-risk medical patients) up to 35 days (patients undergoing knee or hip arthroplasty)., ${ }^{2,14}$ Patients with acute VTE (deep vein thrombosis or pulmonary embolism) should receive low-molecular-weight heparin, unfractionated heparin, or fondaparinux for at least five days, with initiation of warfarin on the first day of therapy and continuation of warfarin for at least three months. ${ }^{23}$

\section{Patient safety initiatives}

Maintaining safety in patients at risk of thromboembolic events has two major components, ie, providing adequate anticoagulation, and balancing thrombotic and hemorrhagic risk. The importance of these two components is evident from the emphasis given to them by health care policy makers. $^{30-34}$

Anticoagulation is underused in many patient populations. For example, only about two-thirds of patients at high or very high risk of stroke because of AF receive oral anticoagulants or low-molecular-weight heparin. ${ }^{35}$ Widespread underuse of anticoagulation in patients with bioprosthetic heart valves has also been documented: the multinational ACTION registry showed that after the first postoperative months, 39\% of study centers did not prescribe anticoagulants to patients who had undergone bioprosthetic aortic valve replacement. ${ }^{36}$ Shorter-term anticoagulation treatment, recommended for hip and knee arthroplasty patients, appears to be more easily managed. The Hip and Knee Registry documented the use of some form of VTE thromboprophylaxis in $99 \%$ of patients undergoing arthroplasty of the hip $(\mathrm{n}=9327)$ or knee $(\mathrm{n}=13,846)$ at 319 hospitals in 42 states between 1996 and $2001 .^{37}$

Underuse of anticoagulation prompted the Agency for Healthcare Research and Quality to define "postoperative pulmonary embolism or deep vein thrombosis" as one of 20 hospital-level patient safety indicators. Quality measures assessed by the Agency for Healthcare Research and Quality include determination of the number of patients with confirmed VTE who receive overlapping parenteral anticoagulation and warfarin therapy. ${ }^{30}$ The Agency for Healthcare Research and Quality mandates that if overlap therapy is not administered for at least five days, with an INR of at least 2.0 prior to discontinuation of parenteral anticoagulation, the patient must be discharged on both medications. $^{30}$

National Quality Forum performance measures to improve safety in anticoagulated AF patients include the number of patients with deep vein thrombosis or pulmonary embolism receiving anticoagulation for at least three months after diagnosis, the number of patients experiencing VTE during hospitalization who did not receive prior VTE prophylaxis, and the percentage of adult patients undergoing procedures for which VTE prophylaxis is indicated who received periprocedural thromboprophylaxis. ${ }^{30}$

The Center for Medicare and Medicaid Services also emphasizes adequate provision of anticoagulation. ${ }^{33,34}$ The Center for Medicare and Medicaid Services Physician Quality Reporting Initiative measures include the percentage of adult patients undergoing a procedure for which VTE prophylaxis is indicated who actually receive thromboprophylaxis. ${ }^{34}$ 
The Center for Medicare and Medicaid Services has designated VTE following hip or knee arthroplasty as a hospital-acquired condition. ${ }^{33}$

Organizations such as the Joint Commission and the National Quality Forum have developed patient safety initiatives around anticoagulation therapy. For example, the Joint Commission identified complexity of dosing, insufficient anticoagulation monitoring, and difficulties in ensuring compliance with outpatient therapy as common reasons for adverse events in patients receiving anticoagulation. ${ }^{31,32}$ In 2010, the Joint Commission published a list of standardized practices to further National Patient Safety Goal 3E, ie, reduction of the likelihood of patient harm associated with the use of anticoagulant therapy in ambulatory, hospital, critical access hospital, and long-term care settings. ${ }^{31,32}$

Among the performance measures defined by the National Quality Forum to benchmark safe use of anticoagulation ${ }^{30,38}$ are: the percentage of patients treated with warfarin who receive INR testing within 3-7 days of beginning treatment with an interacting anti-infective; the average percentage of monthly intervals in which patients on warfarin do not receive INR testing; and the number of patients with confirmed VTE who are discharged on warfarin with written discharge instructions that address compliance, diet, monitoring, and information about the potential for adverse drug reactions/interactions. ${ }^{30,38}$ This last measure acknowledges the importance of the hospital discharge process and transitions of care in keeping anticoagulated patients safe. ${ }^{30}$

\section{Hospital discharge protocol}

The transition from inpatient to outpatient care, if poorly managed, may adversely affect health outcomes. ${ }^{5,39}$ Approximately $50 \%$ of patients experience a medical error after hospital discharge; almost one quarter experience adverse events, a substantial proportion of which are drugrelated. ${ }^{39,40}$ About $50 \%$ of drug-related adverse events could be either prevented or lessened. ${ }^{5}$

Standards for safe discharge and medication reconciliation across the continuum of care have been published by Project Re-engineered Discharge, the National Quality Forum, and the Joint Commission, ${ }^{40}$ and care transitions are now assessed as part of the National Quality Forum's performance measures. Project Re-engineered Discharge recommends a multistep process to prevent medication errors, educate patients, and ensure that outpatient care providers have the information necessary to continue safe and effective treatment. ${ }^{40}$ In a separate initiative, a consensus published by six US medical societies provides a framework for standards to address quality gaps in transitions between inpatient and outpatient settings. ${ }^{41}$

Key components of the hospital discharge process are shown in Table 3. At a minimum, they include a written discharge summary to the clinician who is assuming postdischarge care; education for patients about their diagnosis, hospital course, and future medical needs; medication reconciliation; and arrangement of post-discharge services, such as follow-up appointments and coagulation testing. ${ }^{40}$

Follow-up immediately after discharge is particularly important for patients on the older anticoagulants such as warfarin or heparinoids, because these drugs are commonly associated with post-discharge drug-related adverse events. ${ }^{42}$ Notably, the information necessary to prescribe anticoagulation safely after discharge is missing from many discharge summaries. ${ }^{43}$

Table 3 Components of a high-quality discharge system ${ }^{40}$

\begin{tabular}{|c|c|}
\hline $\begin{array}{l}\text { Project Re-Engineered } \\
\text { Discharge }\end{array}$ & $\begin{array}{l}2009 \text { national quality } \\
\text { forum }\end{array}$ \\
\hline $\begin{array}{l}\text { Educate the patient about diagnosis } \\
\text { during hospitalization }\end{array}$ & $\begin{array}{l}\text { Prepare a written discharge } \\
\text { plan }\end{array}$ \\
\hline $\begin{array}{l}\text { Make appointments for clinician } \\
\text { follow-up and post-discharge } \\
\text { testing; identify and resolve barriers } \\
\text { to follow-up care }\end{array}$ & $\begin{array}{l}\text { Prepare a written discharge } \\
\text { summary } \\
\text { Provide a discharge } \\
\text { summary to clinician who }\end{array}$ \\
\hline $\begin{array}{l}\text { Talk to the patient about testing } \\
\text { done in the hospital and who }\end{array}$ & $\begin{array}{l}\text { will provide care after } \\
\text { discharge }\end{array}$ \\
\hline $\begin{array}{l}\text { will follow up on results } \\
\text { Organize post-discharge services; } \\
\text { identify and resolve barriers to } \\
\text { receiving services }\end{array}$ & $\begin{array}{l}\text { Develop an institutional } \\
\text { system to confirm receipt } \\
\text { of the discharge summary } \\
\text { by clinician }\end{array}$ \\
\hline $\begin{array}{l}\text { Medication reconciliation: counsel } \\
\text { the patient about medications and } \\
\text { identify barriers to adherence and } \\
\text { compliance }\end{array}$ & \\
\hline $\begin{array}{l}\text { Reconcile the discharge plan } \\
\text { with evidence-based guidelines }\end{array}$ & \\
\hline $\begin{array}{l}\text { Educate the patient on problem- } \\
\text { solving strategies, including contacting } \\
\text { the primary care physician }\end{array}$ & \\
\hline $\begin{array}{l}\text { Expedite transmission of the discharge } \\
\text { summary to clinician and services that } \\
\text { will be involved post-discharge care }\end{array}$ & \\
\hline $\begin{array}{l}\text { Assess the patient's understanding of } \\
\text { the discharge plan; ask patients to } \\
\text { explain in their own words; identify } \\
\text { and resolve barriers to understanding }\end{array}$ & \\
\hline $\begin{array}{l}\text { Provide patient with a written } \\
\text { summary detailing clinical course, } \\
\text { follow-up, and medication instructions }\end{array}$ & \\
\hline $\begin{array}{l}\text { Call the patient } 2-3 \text { days after discharge } \\
\text { to review the plan and address problems }\end{array}$ & \\
\hline
\end{tabular}

Note: Copyright (C) 2010 John Wiley and Sons. Adapted with permission from Tomás Villanueva. Transitioning the patient with acute coronary syndrome from inpatient to primary care. Journal of Hospital Medicine. 2010;S8-SI4. ${ }^{40}$ 
Patients discharged on low-molecular-weight heparin, warfarin, or heparin-warfarin overlap require particular care. Clinicians must teach patients discharged on a lowmolecular-weight heparin such as enoxaparin how to selfadminister their injections or arrange for home health care personnel to perform this task. Periodic complete blood counts (including platelets to assess for heparin-induced thrombocytopenia) and stool occult blood tests should be conducted during anticoagulant treatment; anti-FXa testing may be useful in patients with any of the following conditions: bleeding complications, extremes of body weight $(<50 \mathrm{~kg}$ and $>150 \mathrm{~kg}$ ), creatinine clearance $<40 \mathrm{~mL}$ per minute, pregnancy, acute burns, or recurrent thrombosis despite drug treatment. Low-molecular-weight heparin-treated patients should not take medications that increase the risk of hemorrhage, such as other anticoagulants, platelet inhibitors, nonsteroidal anti-inflammatory drugs, dipyridamole, or sulfinpyrazone. If coadministration is essential, the patient should be closely monitored.

Patients discharged on warfarin therapy require a number of special considerations, in particular, frequent monitoring of anticoagulant effect until both dose and INR are stable. ${ }^{14}$ The frequency of INR measurement should be increased in the period immediately after discharge and whenever other medications, whether prescription, over-the-counter, or herbal, are started, discontinued, or taken irregularly.

Patients discharged on heparin-warfarin overlap therapy also require special monitoring. For those with acute thrombosis, health care providers must ensure that full-dose heparin is continued for a minimum of five days and until the target INR has been achieved, at which time heparin should be discontinued.

Factors pertinent to the hospital discharge process (eg, timing of discharge post admission/intervention, total duration of anticoagulation, possible anticoagulant regimens at time of discharge, likely post-discharge anticoagulant regimen) differ depending on the characteristics of the anticoagulated patient. Table 4 summarizes these factors for patients with AF, prosthetic valve placement, and acute VTE, and for those who have undergone arthroplasty.

\section{Barriers to safe and effective anticoagulation during care transitions}

Barriers to safe and effective anticoagulation during care transitions may occur at the level of the health care system, the physician, or the patient. Within health care systems, poor communication between hospitalists and primary care providers at the time of discharge is a common problem. ${ }^{5,40}$ Among physicians, inaccurate perceptions of benefit to risk, ${ }^{44}$ inadequate knowledge of guideline recommendations ${ }^{45}$ and reluctance to prescribe anticoagulation in patients with a history of minor bleeding within the previous three months or severe bleeding more than three months previously ${ }^{46}$ may all contribute to underuse of anticoagulation. Among patients, lack of adherence with medication after discharge, ${ }^{1,47,48}$ unwillingness to undergo repeated testing, ${ }^{46}$ and inadequate knowledge about the risk of thromboembolism and the efficacy of anticoagulation ${ }^{49}$ are documented reasons for unsafe or ineffective anticoagulation. The cost and inconvenience of monitoring may also be substantial barriers in the post-discharge period. ${ }^{50-52}$

Some barriers may be addressed by improvements in education and health care organization. For example, at the time of discharge, the hospital should provide the patient's primary care physician with a discharge summary including, at minimum, the diagnosis, discharge medications, target INR, results of procedures, follow-up needs, pending test results, and suggested next steps. ${ }^{39}$ At the time of discharge, it is also advisable to give the patient a list of the most pertinent information. ${ }^{39}$ Full medication reconciliation should occur at care transitions. ${ }^{39}$ Efforts to educate primary care physicians about the importance of thromboprophylaxis may help to improve the widespread underuse of anticoagulants in at-risk outpatients $\mathrm{s}^{36,53}$ and ensure that anticoagulants prescribed at the time of hospital discharge are not discontinued prematurely. Efforts to improve physician-patient communication ${ }^{39}$ and educate patients about their level of thromboembolic risk and the benefits of anticoagulation may also be beneficial. ${ }^{49}$ Certainly, the evidence shows that educational interventions are effective in reducing the incidence of hemorrhagic and thromboembolic events in outpatients treated with warfarin for VTE. ${ }^{54}$

These strategies may help overcome educational and organizational barriers to safe and effective anticoagulation, but they cannot address the barriers inherent in warfarin, the cornerstone of oral anticoagulation for longer than 50 years. ${ }^{1}$ Such barriers include a narrow therapeutic index, the influence of cytochrome P450 (CYP)2C9 and vitamin K epoxide reductase polymorphisms on warfarin pharmacokinetics and pharmacodynamics, interindividual variability in dose requirements, food-drug and drug-drug interactions, and a complex regimen. ${ }^{1,55,56}$ These challenges highlight the need for effective and safe options for long-term outpatient use.

\section{Novel oral anticoagulants}

Three new novel oral anticoagulants are approved in the US, ie, dabigatran, rivaroxaban, and apixaban, to reduce the risk 


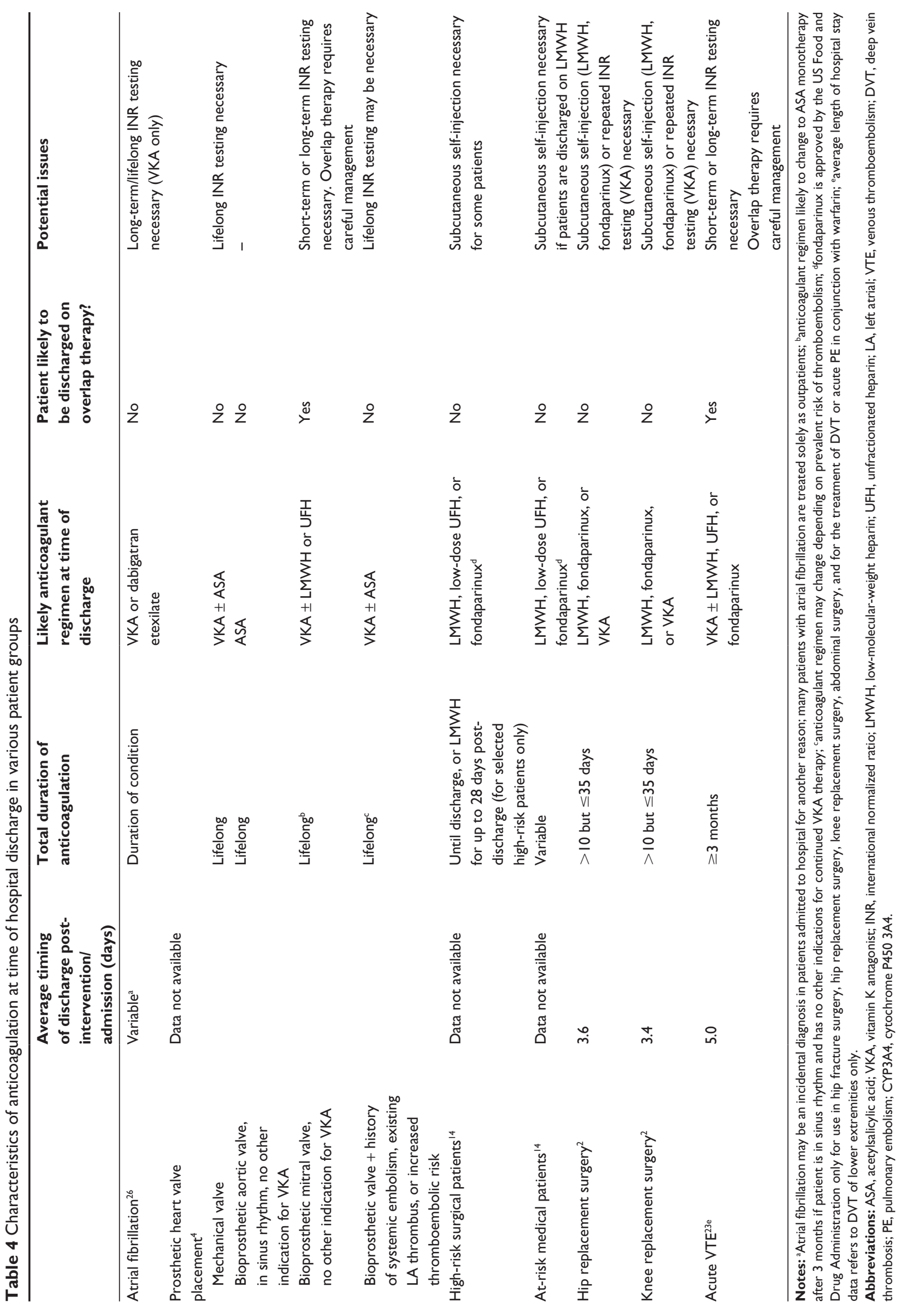


of stroke and systemic embolism in patients with AF, and rivaroxaban also for the treatment of deep vein thrombosis and pulmonary embolism, and for the prophylaxis of deep vein thrombosis, which may lead to pulmonary embolism following hip and knee replacement surgery. ${ }^{57,58}$ These agents offer efficacy at least equal to that of warfarin, as well as the potential for safer and better managed anticoagulation during transitions of care. The key clinical trials are reviewed here, and the major clinical considerations for each drug are summarized.

\section{Dabigatran etexilate}

Dabigatran etexilate is an oral, direct thrombin inhibitor approved by the FDA to reduce the risk of SSE in patients with nonvalvular AF. ${ }^{57}$ It was the first oral anticoagulant alternative to warfarin approved in the US for use in this patient group. Dabigatran etexilate (active moiety, dabigatran) is administered orally at a fixed dose of $150 \mathrm{mg}$ twice daily for most patients, with a reduced dose of $75 \mathrm{mg}$ twice daily recommended for patients with creatinine clearance of $15-30 \mathrm{~mL}$ per minute. ${ }^{57}$ The anticoagulant activity and half-life of dabigatran are increased in patients with renal impairment; no dosing recommendation can be made for patients with creatinine clearance $<15 \mathrm{~mL}$ per minute. Periodic assessment of renal function is recommended. The only drug interactions with a warning against coadministration in the prescribing information are with P-glycoprotein inducers such as rifampin and, in the case of patients with creatinine clearance of $30-50 \mathrm{~mL}$ per minute, dronedarone and systemic ketoconazole. ${ }^{57}$ Concomitant administration of P-glycoprotein inhibitors in patients with renal impairment may be expected to result in increased exposure to dabigatran compared with that seen with either factor alone. ${ }^{57}$ No dietary interactions are reported. ${ }^{57}$ Dabigatran does not require routine blood coagulation monitoring, but when the extent of anticoagulation needs to be assessed, use of the activated partial thromboplastin time or ecarin clotting time, and not the INR, is recommended. ${ }^{57}$

The Phase III RE-LY trial compared open-label, doseadjusted warfarin with two blinded doses of dabigatran etexilate for the primary outcome of SSE in 18,113 patients with nonvalvular AF. ${ }^{59}$ For warfarin-treated patients $(n=6022)$, the mean percentage of the study period during which the INR was within therapeutic range was $64 \%$. The $150 \mathrm{mg}$ twice daily dose of dabigatran etexilate was superior to warfarin for the prevention of SSE (1.11\% versus $1.71 \%$ per year, respectively; $P<0.001$ for superiority), with a similar risk of the primary safety end point of major hemorrhage $(3.32 \%$ and $3.57 \%$ per year, respectively; $P=0.32) .{ }^{59,60}$ In contrast, rates of SSE were similar in the dabigatran etexilate $110 \mathrm{mg}$ twice daily and warfarin groups $(1.54 \%$ and $1.71 \%$ per year, respectively; $P=0.30)$. However, dabigatran etexilate $110 \mathrm{mg}$ twice daily was associated with a lower rate of major hemorrhage than warfarin $(2.87 \%$ versus $3.57 \%$ per year, respectively; $P=0.003) .{ }^{59,60}$ Although rates of life-threatening bleeding, intracranial bleeding, and major or minor bleeding were higher with warfarin than with either dose of dabigatran ( $P<0.05$ for all comparisons), the rate of major gastrointestinal bleeding was significantly higher with the $150 \mathrm{mg}$ dose of dabigatran than with warfarin. ${ }^{59,60}$ It is noteworthy that the $110 \mathrm{mg}$ twice daily dose is not approved by the FDA.

Dabigatran etexilate was compared with enoxaparin for thromboprophylactic efficacy in four trials in knee and hip arthroplasty patients. In three trials, dabigatran etexilate twice daily was at least as effective as enoxaparin $40 \mathrm{mg}$ once daily for prevention of VTE after total knee and hip replacement surgery, with a similar safety profile. ${ }^{61-63}$ The fourth trial compared dabigatran etexilate with enoxaparin $30 \mathrm{mg}$ twice daily (US regimen) in patients undergoing knee arthroplasty. ${ }^{64}$ The risk of bleeding was similar in the dabigatran etexilate-treated and enoxaparin-treated patients; however, dabigatran etexilate failed to equal the efficacy of enoxaparin in this trial. ${ }^{64}$ Compared with warfarin (RE-MEDY) and with placebo (RE-SONATE) in double-blind randomized trials of patients with venous thromboembolism who had completed at least three initial months of therapy, dabigatran $150 \mathrm{mg}$ twice daily was noninferior to warfarin and significantly superior to placebo in reducing the rate of recurrent thromboembolism. ${ }^{65}$ There were fewer major bleeding events and significantly fewer clinically relevant nonmajor bleeding events compared with the active control, but a significantly higher risk of major or clinically relevant nonmajor bleeding compared with placebo. ${ }^{65}$

\section{Rivaroxaban}

The oral FXa inhibitor rivaroxaban is approved by the FDA for reduction of the risk of SSE in patients with nonvalvular $\mathrm{AF}$, for the treatment of deep vein thrombosis and pulmonary embolism and to reduce the risk of their recurrence; and for the prophylaxis of deep vein thrombosis, which may lead to pulmonary embolism following knee or hip replacement surgery. ${ }^{58}$ Rivaroxaban is the first new oral anticoagulant to be approved in the US for the latter two indications. This agent is given at a dose of $10 \mathrm{mg}$ /day for patients with a 
creatinine clearance $\geq 30 \mathrm{~mL}$ per minute; caution should be exercised when rivaroxaban is administered to patients with a creatinine clearance of $30-50 \mathrm{~mL}$ per minute. Routine blood coagulation monitoring is not required. Coadministration with other anticoagulants, eg, clopidogrel, and combined P-glycoprotein and strong CYP3A4 inhibitors and inducers should be avoided. In patients with renal impairment, coadministration with a combined P-glycoprotein inducer and a weak or moderate CYP3A4 inhibitor should be avoided, unless the potential benefit outweighs the increased bleeding risk associated with increased rivaroxaban exposure. No dietary interactions are known.

Rivaroxaban was compared with the low-molecular-weight heparin, enoxaparin, in four Phase III clinical trials involving patients undergoing hip or knee arthroplasty. The European enoxaparin regimen (40 mg daily) was used in three of these trials and the US regimen (30 mg twice daily) was used in the other. Rivaroxaban was significantly more effective than enoxaparin at preventing VTE in all four trials, with no significant increase in the risk of major bleeding. ${ }^{66-69}$

The efficacy of rivaroxaban and warfarin was compared in 14,264 patients with nonvalvular AF in the Phase III ROCKET-AF trial. ${ }^{70}$ The results suggest that rivaroxaban may be an alternative to warfarin for AF patients who are at moderate or high risk of stroke. Rivaroxaban was noninferior to warfarin for preventing SSE both in the intentto-treat population $(2.1 \%$ and $2.4 \%$ per year, respectively; $P<0.0001$ for noninferiority) and the per protocol population (1.7\% versus $2.2 \%$ per year, respectively; $P<0.0001$ for noninferiority). ${ }^{70}$ Among patients treated with warfarin, the mean proportion of time in which INR values (calculated from all INR values during the study and for seven days after warfarin interruption) were within therapeutic range (2.0-3.0) was 55\%, which was lower than in previous studies of other new anticoagulants in patients with AF (range $64 \%-68 \%) .^{70}$ The incidence of major and clinically relevant nonmajor bleeding, the primary safety end point, was similar in the rivaroxaban and warfarin groups (14.9\% and $14.5 \%$ per year, respectively; $P=0.44)$. Although fatal bleeding and bleeding at critical anatomic sites were less frequent among rivaroxaban-treated patients, major bleeding from a gastrointestinal site was more common in the rivaroxaban group, with 224 bleeding events (3.2\%) compared with 154 in the warfarin group $(2.2 \%, P<0.001){ }^{.70}$

\section{Apixaban}

The oral, direct FXa inhibitor, apixaban, gained FDA approval at the end of December 2012 to reduce the risk of stroke and systemic embolism in patients with nonvalvular AF. In clinical trials, apixaban was administered as a fixed dose of $2.5 \mathrm{mg}$ or $5.0 \mathrm{mg}$ twice daily without routine coagulation monitoring. ${ }^{71-74}$ Because apixaban is metabolized by the CYP3A4 system, strong dual inhibitors of CYP3A4 and P-glycoprotein increase blood levels of apixaban; the apixaban dose should be reduced to $2.5 \mathrm{mg}$ or concomitant use avoided. ${ }^{75,76}$ Moreover, coadministration of an antiplatelet agent or a nonsteroidal anti-inflammatory drug with an anticoagulant generally increases bleeding risk, and caution is advised if clopidogrel, in particular, is coadministered with apixaban. ${ }^{75,76}$

Comparison with the low-molecular-weight heparin, enoxaparin, in 3195 patients undergoing elective knee replacement in the Phase III ADVANCE-1 trial showed that oral apixaban $2.5 \mathrm{mg}$ twice daily was superior to subcutaneous enoxaparin $30 \mathrm{mg}$ every 12 hours in preventing the composite primary outcome of asymptomatic and symptomatic deep vein thrombosis, nonfatal pulmonary embolism, and all-cause mortality, which occurred at a rate of $9.0 \%$ with apixaban versus $8.8 \%$ with enoxaparin. ${ }^{74}$ The composite incidence of major bleeding and clinically relevant nonmajor bleeding was $2.9 \%$ with apixaban versus $4.3 \%$ with enoxaparin $(P=0.03) .{ }^{74}$ Comparable results were noted in the Phase III ADVANCE-3 trial, in which the same safety and efficacy end points were used. ${ }^{73}$ A total of 5407 patients undergoing elective hip replacement were randomized to treatment with either oral apixaban $2.5 \mathrm{mg}$ twice daily initiated 12-24 hours after closure of the surgical wound, or subcutaneous enoxaparin $40 \mathrm{mg}$ once every 24 hours and initiated 12 hours before surgery. ${ }^{73}$ In patients undergoing hip replacement, thromboprophylaxis with apixaban, compared with enoxaparin, was associated with lower rates of venous thromboembolism, with no increase in bleeding risk. ${ }^{73}$

Apixaban was also compared with acetylsalicylic acid for prevention of SSE in the Phase III AVERROES study of AF patients with at least one additional risk factor for stroke who were unsuitable for or intolerant of warfarin therapy. ${ }^{72}$ Of the 5599 patients enrolled, 2216 (40\%) had previously received and discontinued warfarin therapy; for 932 of these patients (42\%), INR could not be maintained in the therapeutic range. In the case of 2387 patients (43\%), the physician had determined that INR measurements could not or were unlikely to be obtained at the requested intervals. Warfarin therapy was considered inappropriate for 1195 patients $(21 \%)$ who had only a moderate risk of stroke, as assessed by a $\mathrm{CHADS}_{2}$ score of 1 . There were 2092 patients $(37 \%)$ who did not want to take warfarin, and 
for 815 of them (15\%), this was the only reason that warfarin therapy was unsuitable. The trial was stopped early because apixaban was clearly superior for the prevention of stroke and embolic events (apixaban $5 \mathrm{mg}$ twice daily, annual risk $1.6 \%$ versus acetylsalicylic acid $81-324 \mathrm{mg} /$ day, annual risk $3.7 \% ; P<0.001){ }^{72}$ The superior efficacy of apixaban was not associated with any significant increase in bleeding risk (major bleeding: apixaban annual risk 1.4\%; acetylsalicylic acid annual risk 1.2\%; hazard ratio 1.13 ; $95 \%$ confidence interval $0.74-1.75 ; P=0.57) .^{72}$

The ARISTOTLE trial compared the thromboprophylactic effects of apixaban with those of warfarin in patients with nonvalvular $\mathrm{AF}^{77}$ The results indicated that apixaban was superior to warfarin for the prevention of SSE, caused less bleeding, and resulted in lower mortality. ${ }^{71,77}$

\section{Future of anticoagulation}

For many years, warfarin has been the cornerstone of longterm anticoagulant therapy, ${ }^{1}$ and it is widely used both during hospitalization and after discharge. Many anticoagulated patients receive warfarin at hospital discharge or when they are transitioned from parenteral to oral anticoagulant therapy. New oral anticoagulants may provide advantages over traditional warfarin both during long-term therapy and during transitions of care. Such advantages include fixed dosing, reduced potential for drug-drug interactions, and lack of a requirement for coagulation monitoring or dietary modification. It must be kept in mind, however, that the three new oral anticoagulants approved to date by the FDA are indicated only for the reduction of stroke risk in patients with nonvalvular AF and, in the case of rivaroxaban, for the treatment and prevention of deep vein thrombosis and pulmonary embolism, and for the prophylaxis of deep vein thrombosis which may lead to pulmonary embolism following hip and knee replacement surgery. ${ }^{57,58}$ Data to support wider indications for the new anticoagulants are not yet available. A European trial (RE-ALIGN) comparing the safety and efficacy of dabigatran etexilate and warfarin in patients with mechanical prosthetic heart valves was stopped early after it was found that patients receiving dabigatran etexilate were more likely to experience strokes, heart attacks, and thrombotic events than were patients on warfarin. ${ }^{78}$ Patients on dabigatran etexilate also experienced more bleeding after valve surgery than those on warfarin. ${ }^{78}$ Dabigatran etexilate is approved only for patients with nonvalvular $\mathrm{AF}$ and is contraindicated in patients with mechanical prosthetic valves. ${ }^{78}$ FDA-approved labels for the new novel anticoagulants warn that discontinuing anticoagulants for active bleeding, elective surgery, or invasive procedures, places patients at an increased risk of stroke. Clinicians are advised to minimize lapses in therapy. Warfarin, by contrast, is indicated for the prophylaxis and treatment of venous thrombosis and its extension, pulmonary embolism; for the prophylaxis and treatment of thromboembolic complications associated with $\mathrm{AF}$ and/or cardiac valve replacement; and for reducing the risk of death, recurrent myocardial infarction, and thromboembolic events such as SSE after myocardial infarction. New novel anticoagulants have been approved in many countries worldwide, including Canada, Japan, South America, and the European Union.

The recent introduction of new oral anticoagulants has the potential to improve the care of patients with nonvalvular AF who are at risk of stroke and for patients undergoing surgery for knee or hip replacement. These drugs may have advantages over warfarin and low-molecular-weight heparin during the transition of care from inpatient to outpatient status, a period during which patients are especially vulnerable. ${ }^{7-9}$ Use of one of the new oral anticoagulants during the transition period could free both the patient and the physician from the need for frequent coagulation monitoring and dose adjustment, from challenges presented by diet or concomitant medications and, if the same drug were used during both inpatient and outpatient periods, from problems resulting from inadequate overlap. Anticoagulation with the same oral drug throughout the period of hospitalization and care transition offers an obvious advantage over the current parenteral or parenteral-oral overlap regimens. Moreover, there is no evidence that the pharmacokinetics of the new anticoagulants are subject to significant pharmacogenetic variability.

As noted earlier, health care policy organizations have developed performance measures that emphasize the importance of providing adequate anticoagulation and optimally managing anticoagulated patients while making efforts to improve safety during care transitions. Evidence of anticoagulant efficacy, safety, and a low risk of over-coagulation documented in clinical trials suggests that dabigatran etexilate, rivaroxaban, and apixaban have the potential to improve patient management and safety during the transition from inpatient to outpatient status.

\section{Summary}

Transitions of care can be difficult to manage effectively in anticoagulated patients. Suboptimal management, which is widespread during care transitions, may result from inadvertent cessation of therapy, medication discrepancies, 
and fluctuations in or inadequate monitoring of anticoagulant effect. These events all have the potential to hinder the achievement of treatment goals and compromise patient safety. Dabigatran etexilate, rivaroxaban, and apixaban exemplify an innovative approach to both short-term and long-term thromboprophylaxis for patients at increased risk for thromboembolism. These agents have the potential to simplify anticoagulation while increasing safety during transitions of care. They offer advantages over conventional anticoagulants and enhance the range of treatment options available to physicians who must negotiate a safe and effective passage between the risks of thrombosis and hemorrhage in anticoagulant therapy.

\section{Acknowledgment}

The author acknowledges the editorial assistance of Medicus and the UBC-Envision Group, the services of which were funded by Boehringer Ingelheim Pharmaceuticals Inc.

\section{Disclosure}

The author is a consultant to Boehringer-Ingelheim, SanofiAventis, Otsuka, Janssen, and Gilead, and is on advisory boards for Ortho-McNeil, Medtronic, and Daiichi Sankyo. The author has no other conflicts of interest in this work.

\section{References}

1. Ansell J, Hirsh J, Poller L, Bussey H, Jacobson A, Hylek E. The pharmacology and management of the vitamin K antagonists: the Seventh ACCP Conference on Antithrombotic and Thrombolytic Therapy. Chest. 2004;126:204S-233S.

2. Falck-Ytter Y, Francis CW, Johanson NA, et al. Antithrombotic Therapy and Prevention of Thrombosis, 9th ed: American College of Chest Physicians Evidence-Based Clinical Practice Guidelines. Chest. 2012;141(Suppl 2):e278S-e325S.

3. Hart RG, Pearce LA, Aguilar MI. Meta-analysis: antithrombotic therapy to prevent stroke in patients who have nonvalvular atrial fibrillation. Ann Intern Med. 2007;146:857-867.

4. Whitlock RP, Sun JC, Fremes SE, Rubens FD, Teoh KH. Antithrombotic and thrombolytic therapy for valvular disease. Antithrombotic Therapy and Prevention of Thrombosis, 9th ed: American College of Chest Physicians Evidence-Based Clinical Practice Guidelines. Chest. 2012;141(Suppl 2):e576S-e600S.

5. Kripalani S, Jackson AT, Schnipper JL, Coleman EA. Promoting effective transitions of care at hospital discharge: a review of key issues for hospitalists. J Hosp Med. 2007;2:314-323.

6. Bell CM, Rahimi-Darabad P, Orner AI. Discontinuity of chronic medications in patients discharged from the intensive care unit. $J$ Gen Intern Med. 2006;21:937-941.

7. Jackson SL, Peterson GM, Vial JH, Jupe DM. Improving the outcomes of anticoagulation: an evaluation of home follow-up of warfarin initiation. J Intern Med. 2004;256:137-144.

8. Tjia J, Bonner A, Briesacher BA, McGee S, Terrill E, Miller K. Medication discrepancies upon hospital to skilled nursing facility transitions. $J$ Gen Intern Med. 2009;24:630-635.

9. Phillips KW, Ansell J. Outpatient management of oral vitamin K antagonist therapy: defining and measuring high-quality management. Expert Rev Cardiovasc Ther. 2008;6:57-70.
10. Arixtra $^{\circledR}$ (fondaparinux sodium) product information. Available from: http://us.gsk.com/products/assets/us_arixtra.pdf. Accessed August 1, 2012.

11. Lovenox ${ }^{\circledR}$ (enoxaparin sodium) product information. Available from: http://products.sanofi.us/lovenox/lovenox.html. Accessed August 1, 2012.

12. Coumadin ${ }^{\circledR}$ (warfarin sodium) product information. Available from: http://packageinserts.bms.com/pi/pi_coumadin.pdf. Accessed August 1, 2012.

13. Runciman WB, Roughead EE, Semple SJ, Adams RJ. Adverse drug events and medication errors in Australia. Int J Qual Health Care. 2003;15 Suppl 1:i49-i59.

14. Guyatt GH, Akl EA, Crowther M, Gutterman DD, Schuünemann HJ; for the American College of Chest Physicians. Antithrombotic Therapy and Prevention of Thrombosis Panel. Antithrombotic Therapy and Prevention of Thrombosis, 9th ed: American College of Chest Physicians Evidence-Based Clinical Practice Guidelines. Chest. 2012; 141(Suppl 2):7S-47S.

15. Turpie AG. Fondaparinux: a Factor Xa inhibitor for antithrombotic therapy. Expert Opin Pharmacother. 2004;5:1373-1384.

16. You JJ, Singer DE, Howard PA, et al. Antithrombotic Therapy for Atrial Fibrillation. Antithrombotic Therapy and Prevention of Thrombosis, 9th ed: American College of Chest Physicians Evidence-Based Clinical Practice Guidelines. Chest. 2012;141(Suppl 2): e531S-e575S.

17. Wolf PA, Abbott RD, Kannel WB. Atrial fibrillation as an independent risk factor for stroke: the Framingham Study. Stroke. 1991;22: 983-988.

18. Bluestein D, Yin W, Affeld K, Jesty J. Flow-induced platelet activation in mechanical heart valves. J Heart Valve Dis. 2004;13:501-508.

19. Yoganathan AP, Chandran KB, Sotiropoulos F. Flow in prosthetic heart valves: state-of-the-art and future directions. Ann Biomed Eng. 2005;33: 1689-1694.

20. Cannegieter SC, Rosendaal FR, Briet E. Thromboembolic and bleeding complications in patients with mechanical heart valve prostheses. Circulation. 1994;89:635-641.

21. Butchart EG, Ionescu A, Payne N, Giddings J, Grunkemeier GL, Fraser AG. A new scoring system to determine thromboembolic risk after heart valve replacement. Circulation. 2003;108 Suppl 1: II68-II74.

22. Kroegel C, Reissig A. Principal mechanisms underlying venous thromboembolism: epidemiology, risk factors, pathophysiology and pathogenesis. Respiration. 2003;70:7-30.

23. Kearon C, Akl EA, Comerota AJ, et al. Antithrombotic Therapy for VTE Disease: Antithrombotic Therapy and Prevention of Thrombosis, 9th ed: American College of Chest Physicians evidencebased clinical practice guide lines. Chest. 2012;141(Suppl 2): e419S-e494S.

24. Cushman M, Tsai AW, White RH, et al. Deep vein thrombosis and pulmonary embolism in two cohorts: the longitudinal investigation of thromboembolism etiology. Am J Med. 2004;117:19-25.

25. Gage BF, Waterman AD, Shannon W, Boechler M, Rich MW, Radford MJ. Validation of clinical classification schemes for predicting stroke: results from the National Registry of Atrial Fibrillation. JAMA. 2001;285:2864-2870.

26. Camm AJ, Kirchhof P, Lip GY, et al. Guidelines for the management of atrial fibrillation: the Task Force for the Management of Atrial Fibrillation of the European Society of Cardiology (ESC). Europace. 2010;12:1360-1420.

27. Fuster V, Rydén LE, Cannom DS, et al. ACC/AHA/ESC 2006 Guidelines for the Management of Patients with Atrial Fibrillation: a report of the American College of Cardiology/American Heart Association Task Force on Practice Guidelines and the European Society of Cardiology Committee for Practice Guidelines (Writing Committee to Revise the 2001 Guidelines for the Management of Patients With Atrial Fibrillation): developed in collaboration with the European Heart Rhythm Association and the Heart Rhythm Society. Circulation. 2006;114:e257-e354. 
28. Wann LS, Curtis AB, Ellenbogen KA, et al. 2011 ACCF/AHA/HRS focused update on the management of patients with atrial fibrillation (update on dabigatran): a report of the American College of Cardiology Foundation/American Heart Association Task Force on practice guidelines. Circulation. 2011;123:1144-1150.

29. Douketis JD, Spyropoulos AC, Spencer FA, et al. Perioperative management of antithrombotic therapy: Antithrombotic Therapy and Prevention of Thrombosis, 9th ed: American College of Chest Physicians Evidence-Based Clinical Practice Guidelines. Chest. 2012;141(Suppl 2):e326S-e350S.

30. National Quality Forum Performance Measures: Anticoagulation (0373 overlap, $043 \mathrm{AF} /$ flutter, 0503 acute PE, $0581 \mathrm{DVT}, 0593 \mathrm{PE}>3 \mathrm{mo}$, 0624 warfarin, 1525 chronic AC). Available from: http://www. qualityforum.org/Measures_List.aspx $\# \mathrm{p}=2 \& \mathrm{~s}=\mathrm{n} \& \mathrm{so}=\mathrm{a} \& \mathrm{k}=\mathrm{anticoagu}$ lation\&e $=1 \& s t=\& s d=\& m t=\& c s=\& s s=$. Accessed July 27, 2012.

31. Joint Commission National Patient Safety Goals: Anticoagulation. Available from: http://www.jointcommission.org/search/default.aspx? Keywords $=$ anticoagulant $\& \mathrm{f}=$ sitename\&sitename $=$ Joint+Commission Accessed July 27, 2012.

32. Joint Commission. Preventing errors. Available from: http://www. jointcommission.org/search/default.aspx?Keywords=preventing+errors $\& \mathrm{f}=$ sitename\&sitename=Joint+Commission. Accessed July 27, 2012.

33. Center for Medicare and Medicaid Services. Safety topics. Anticoagulation; hospital-acquired conditions. Available from: https:// www.premierinc.com/safety/safety-share/10-08-full-txt.jsp. Accessed July 27, 2012.

34. Center for Medicare and Medicaid Services. Physician Quality reporting Initiative. Anticoagulation. Available from: http://www.cms. gov/Medicare/Quality-Initiatives-Patient-Assessment-Instruments PQRS/index.html?redirect=/PQRI/15_MeasuresCodes.asp. Accessed July 27, 2012.

35. Nabauer M, Gerth A, Limbourg T, et al. The Registry of the German Competence NETwork on Atrial Fibrillation: patient characteristics and initial management. Europace. 2009;11:423-434.

36. Colli A, Verhoye JP, Heijmen R, et al. Antithrombotic therapy after bioprosthetic aortic valve replacement: ACTION Registry survey results. Eur J Cardiothorac Surg. 2008;33:531-536.

37. Anderson FA Jr, Hirsh J, White K, Fitzgerald RH Jr. Temporal trends in prevention of venous thromboembolism following primary total hip or knee arthroplasty 1996-2001: findings from the Hip and Knee Registry. Chest. 2003;124:349S-356S.

38. Agency for Healthcare Research and Quality. National Guidelines Clearinghouse. Available from: http://www.qualitymeasures.ahrq.gov/ hhs-measure-inventory/browse.aspx. Accessed July 27, 2012

39. Kripalani S, LeFevre F, Phillips CO, Williams MV, Basaviah P, Baker DW. Deficits in communication and information transfer between hospital-based and primary care physicians: implications for patient safety and continuity of care. JAMA. 2007;297:831-841.

40. Villanueva T. Transitioning the patient with acute coronary syndrome from inpatient to primary care. $J$ Hosp Med. 2010;5 Suppl 4: S8-S14.

41. Snow V, Beck D, Budnitz T, et al. Transitions of Care Consensus Policy Statement American College of Physicians-Society of General Internal Medicine-Society of Hospital Medicine-American Geriatrics Society-American College of Emergency Physicians-Society of Academic Emergency Medicine. J Gen Intern Med. 2009;24: 971-976.

42. Forster AJ, Murff HJ, Peterson JF, Gandhi TK, Bates DW. Adverse drug events occurring following hospital discharge. J Gen Intern Med. 2005;20:317-323

43. Gandara E, Moniz TT, Ungar J, et al. Deficits in discharge documentation in patients transferred to rehabilitation facilities on anticoagulation: results of a systemwide evaluation. Jt Comm J Qual Patient Saf. 2008;34:460-463.

44. Pradhan AA, Levine MA. Warfarin use in atrial fibrillation: a random sample survey of family physician beliefs and preferences. Can J Clin Pharmacol. 2002;9:199-202.
45. Arepally G, Bauer KA, Bhatt DL, et al. The use of antithrombotic therapies in the prevention and treatment of arterial and venous thrombosis: a survey of current knowledge and practice supporting the need for clinical education. Crit Pathw Cardiol. 2010;9: 41-48.

46. Ingelgard A, Hollowell J, Reddy P, Gold K, Tran K, Fitzmaurice D. What are the barriers to warfarin use in atrial fibrillation?: Development of a questionnaire. J Thromb Thrombolysis. 2006;21:257-265.

47. De Schryver EL, van Gijn J, Kappelle LJ, Koudstaal PJ, Algra A. Non-adherence to aspirin or oral anticoagulants in secondary prevention after ischaemic stroke. $J$ Neurol. 2005;252:1316-1321.

48. Kneeland PP, Fang MC. Current issues in patient adherence and persistence: focus on anticoagulants for the treatment and prevention of thromboembolism. Patient Prefer Adherence. 2010;4: $51-60$.

49. Lane DA, Ponsford J, Shelley A, Sirpal A, Lip GY. Patient knowledge and perceptions of atrial fibrillation and anticoagulant therapy: effects of an educational intervention programme. The West Birmingham Atrial Fibrillation Project. Int J Cardiol. 2006;110: 354-358.

50. Jonas DE, Bryant Shilliday B, Laundon WR, Pignone M. Patient time requirements for anticoagulation therapy with warfarin. Med Decis Making. 2010;30:206-216.

51. Jowett S, Bryan S, Mahe I, et al. A multinational investigation of time and traveling costs in attending anticoagulation clinics. Value Health 2008; 11:207-212.

52. McAnulty JH. Barriers to the use of warfarin: potential solutions. J Interv Card Electrophysiol. 2004;10 Suppl 1:17-20.

53. Kowey PR, Reiffel JA, Myerburg R, et al. Warfarin and aspirin use in atrial fibrillation among practicing cardiologist (from the AFFECTS Registry). Am J Cardiol. 2010;105:1130-1134.

54. Pernod G, Labarere J, Yver J, et al. EDUC'AVK: reduction of oral anticoagulant-related adverse events after patient education: a prospective multicenter open randomized study. J Gen Intern Med. 2008;23:1441-1446

55. Hixson-Wallace JA, Dotson JB, Blakey SA. Effect of regimen complexity on patient satisfaction and compliance with warfarin therapy. Clin Appl Thromb Hemost. 2001;7:33-37.

56. Kamali F, Wynne H. Pharmacogenetics of warfarin. Annu Rev Med. 2010;61:63-75.

57. Pradaxa ${ }^{\circledR}$ (dabigatran etexilate) product information. Available from: http://bidocs.boehringer-ingelheim.com/BIWebAccess/ViewServlet. ser?docBase=renetnt\&folderPath=/Prescribing\%20Information/PIs/ Pradaxa/Pradaxa.pdf. Accessed August 1, 2012

58. Xarelto ${ }^{\circledR}$ (rivaroxaban) product information. Available from: http:// www.xareltohcp.com/sites/default/files/pdf/xarelto_0.pdf\#zoom=100. Accessed August 1, 2012

59. Connolly SJ, Ezekowitz MD, Yusuf S, et al. Dabigatran versus warfarin in patients with atrial fibrillation. $N$ Engl J Med. 2009;361:1139-1151.

60 Connolly SJ, Ezekowitz MD, Yusuf S, Reilly PA, Wallentin L. Newly identified events in the RE-LY trial. $N$ Engl J Med. 2010;363: 1875-1876.

61. Eriksson BI, Dahl OE, Rosencher N, et al. Oral dabigatran etexilate vs subcutaneous enoxaparin for the prevention of venous thromboembolism after total knee replacement: the RE-MODEL randomized trial J Thromb Haemost. 2007;5:2178-2185.

62. Eriksson BI, Dahl OE, Rosencher N, et al. Dabigatran etexilate versus enoxaparin for prevention of venous thromboembolism after total hip replacement: a randomised, double-blind, non-inferiority trial. Lancet. 2007;370:949-956.

63. Huo MH, Eriksson BI, Dahl OE, et al; RE-NOVATE II Study Group. Oral dabigatran versus enoxaparin for thromboprophylaxis after primary total hip arthroplasty: The RE-NOVATE II randomised trial. Thromb Haemost. 2011;105:721-729.

64. Ginsberg JS, Davidson BL, Comp PC, et al. Oral thrombin inhibitor dabigatran etexilate vs North American enoxaparin regimen for prevention of venous thromboembolism after knee arthroplasty surgery J Arthroplasty. 2009;24:1-9. 
65. Schulman S, Kearon C, Kakkar AK, et al; for the RE-MEDY and RE-SONATE Trials Investigators. Extended use of dabigatran, warfarin, or placebo in venous thromboembolism. $N$ Engl J Med. 2013;368: 709-718.

66. Lassen MR, Ageno W, Borris LC, et al. Rivaroxaban versus enoxaparin for thromboprophylaxis after total knee arthroplasty. $N$ Engl J Med. 2008;358:2776-2786.

67. Eriksson BI, Borris LC, Friedman RJ, et al. Rivaroxaban versus enoxaparin for thromboprophylaxis after hip arthroplasty. $N$ Engl J Med. 2008;358:2765-2775.

68. Kakkar AK, Brenner B, Dahl OE, et al. Extended duration rivaroxaban versus short-term enoxaparin for the prevention of venous thromboembolism after total hip arthroplasty: a double-blind, randomised controlled trial. Lancet. 2008;372:31-39.

69. Turpie AG, Lassen MR, Davidson BL, et al. Rivaroxaban versus enoxaparin for thromboprophylaxis after total knee arthroplasty (RECORD4): a randomised trial. Lancet. 2009;373:1673-1680.

70. Patel MR, Mahaffey KW, Garg J, et al. Rivaroxaban versus warfarin in nonvalvular atrial fibrillation. $N$ Engl J Med. 2011;365: 883-891.

71. Granger CB, Alexander JH, McMurray JJ, et al. Apixaban versus warfarin in patients with atrial fibrillation. $N$ Engl J Med. 2011;365: 981-992.
72. Connolly SJ, Eikelboom J, Joyner C, et al. Apixaban in patients with atrial fibrillation. $N$ Engl J Med. 2011;364:806-817.

73. Lassen MR, Gallus A, Raskob GE, Pineo G, Chen D, Ramirez LM. Apixaban versus enoxaparin for thromboprophylaxis after hip replacement. $N$ Engl J Med. 2010;363:2487-2498.

74. Lassen MR, Raskob GE, Gallus A, Pineo G, Chen D, Hornick P. Apixaban versus enoxaparin for thromboprophylaxis after knee replacement (ADVANCE-2): a randomised double-blind trial. Lancet. 2010;375:807-815.

75. Walenga JM, Adiguzel C. Drug and dietary interactions of the new and emerging oral anticoagulants. Int J Clin Pract. 2010;64:956-967.

76. Eliquis ${ }^{\circledR}$ (apixaban) product information. Available from: https:// www.hcp.eliquis.com/Pagesindex.aspx. Revised Dec 2012. Accessed January 23, 2013.

77. Lopes RD, Alexander JH, Al-Khatib SM, et al. Apixaban for reduction in stroke and other ThromboemboLic events in atrial fibrillation (ARISTOTLE) trial: design and rationale. Am Heart J. 2010;159:331-339.

78. US Food and Drug Administration. Pradaxa (dabigatran etexilate mesylate): Drug safety comunication - should not be used in patients wth mechanical prosthetic heart valves. Available from: http://www. fda.gov/safety/medwatch/safetyinformation/safetyalertsforhuman medicalproducts/ucm332949.htm. Accessed 25 March, 2013.
Journal of Multidisciplinary Healthcare

\section{Publish your work in this journal}

The Journal of Multidisciplinary Healthcare is an international, peerreviewed open-access journal that aims to represent and publish research in healthcare areas delivered by practitioners of different disciplines. This includes studies and reviews conducted by multidisciplinary teams as well as research which evaluates the results or conduct of such teams or

\section{Dovepress}

healthcare processes in general. The journal covers a wide range of areas and welcomes submission from practitioners at all levels, from all over the world. The manuscript management system is completely online and includes a very quick and fair peer-review system. Visit http://www.dovepress.com/testimonials.php to read real quotes from published authors. 